\title{
ZEB2, a new candidate gene for asplenia
}

\author{
Linda Pons ${ }^{1}$, Sophie Dupuis-Girod ${ }^{1 *}$, Marie-Pierre Cordier ${ }^{1}$, Patrick Edery ${ }^{1,2}$ and Massimiliano Rossi ${ }^{1,2}$
}

\begin{abstract}
Primary asplenia is a rare condition with poorly known etiology. Mowat-Wilson syndrome (MWS) is characterized by typical facial dysmorphisms, intellectual disability, microcephaly, epilepsy and the possible presence of internal organ malformations. It is caused by heterozygous mutations or deletions in the ZEB2 gene. Nearly 180 patients have been reported to date, but only one with asplenia. We report here spleen hypo/aplasia in 4 out of 6 MWS patients, with severe infectious complications for 3 of them. Our report shows that spleen hypo/aplasia is part of the MWS phenotype and makes ZEB2 a possible candidate gene for primary asplenia.
\end{abstract}

Keywords: Mowat-Wilson syndrome, ZEB2, Asplenia

\section{Letters to the editor}

Primary congenital asplenia is a rare condition with poorly known genetic bases. It can be part of multiple congenital abnormalities syndromes or it can be isolated, which is extremely rare with about 70 patients reported to date [1]. Recently Bolze et al. identified heterozygous mutations in the RPSA gene in more than half the patients studied with isolated congenital asplenia [2]. Mowat-Wilson syndrome (MWS, OMIM \#235730) is characterized by typical facial features (large medially sparse eyebrows, hypertelorism, deep set eyes, uplifted ear lobes with central depression, saddle nose and a pointed chin), intellectual disability, microcephaly, epilepsy and congenital malformations including Hirschsprung disease, genito-urinary abnormalities, cardiac defects, corpus callosum agenesis and ocular anomalies [3]. This syndrome was first described in 1998 [4] and is caused by heterozygous mutations or deletions in the Zinc finger E-box-binding homeobox 2 gene (ZEB2) [5,6]. Nearly 180 patients have been reported to date. Asplenia was reported in only one case [7]. Interestingly, it has been shown that ZEB2 has a diffuse expression in several mouse and human organs, including the spleen $[8,9]$.

We report here spleen hypo/aplasia in 4 out of 6 unrelated MWS patients referred to our genetic department, with severe infectious complications for 3 of them.

\footnotetext{
* Correspondence: sophie.dupuis-girod@chu-lyon.fr

${ }^{1}$ Hospices Civils de Lyon, Groupe Hospitalier Est, Service de Génétique et Centre de référence des anomalies du développement, Bron F-69677, France Full list of author information is available at the end of the article
}

The first patient is a female born to unrelated parents, presenting with a typical facies, microcephaly, postnatal short stature, developmental delay, corpus callosum agenesis, ventricular septal defect, strabismus and left dimmed vision. A de novo c.2083C > T heterozygous mutation of the $Z E B 2$ gene was identified, thus confirming the diagnosis. At the age of 8 months, she suffered from purpura fulminans related to a severe Streptococcus Pneumoniae infection (serotype $12 \mathrm{~F}$ ) with severe necrosis sequellae including the loss of 5 toes and the right heel requiring a skin graft. Asplenia was diagnosed on ultrasound scan (USS).

The second patient is a female born to unrelated parents. Typical dysmorphic features, microcephaly, developmental delay, epilepsy, corpus callosum agenesis, ventricular septal defect and patent ductus arteriosus, club foot and strabismus were consistent with the diagnosis of MWS. A de novo c.600_640dup heterozygous mutation of the ZEB2 gene was identified. At the age of 1 year, she developed meningitis related to Streptococcus Pneumoniae infection (serotype $17 \mathrm{~F}$ on cerebrospinal fluid culture) complicated by moderate intracranial hypertension. USS revealed asplenia.

The third patient is a female born to unrelated parents. She had typical facial dysmorphisms, severe intellectual disability, microcephaly, epilepsy, postnatal short stature, ventricular septal defect, vesico-ureteric reflux, club foot and unilateral choanal atresia. Molecular analysis of the ZEB2 gene showed a de novo c.1762G > T heterozygous mutation. She had two pneumococcal septicemias at the ages of 2 and 3 years. Abdominal USS revealed severe splenic hypoplasia (main axis: $34 \mathrm{~mm}$, average for weight: $80 \mathrm{~mm}$, range 78-87 mm). Howell-Jolly bodies were absent. 
The fourth patient is a female born to non-related parents, presenting with a typical facies, microcephaly, postnatal short stature, developmental delay, epilepsy, atrial septal defect and patent ductus arteriosus, strabismus. A de novo c.2761C $>\mathrm{T}$ heterozygous mutation of the ZEB2 gene was identified confirming the diagnosis of MWS. She had no severe infections. USS showed moderate splenic hypoplasia (main axis: $46 \mathrm{~mm}$, average for weight: $78 \mathrm{~mm}$, range $76-78 \mathrm{~mm}$ ).

The 2 other MWS patients followed in our genetic department had a normal spleen on USS and did not have severe infections.

On one hand, our report shows that spleen hypo/aplasia is a part of the phenotype of MWS. USS should be systematically performed on MWS patients in order to rule out spleen hypo/aplasia because of potential complications' severity. Prevention of severe infections in cases of asplenia or severe hypoplasia, effectively requires appropriate antibiotic prophylaxis and vaccination that can restore the pool of memory B cells [10].

As our cohort only includes 6 MWS subjects, we think that other studies should be done to confirm if asplenia/ spleen hypoplasia is a new feature of this multisystem disorder.

Indeed, the case of asplenia previously reported has a de novo c.696C $>\mathrm{G}$ heterozygous mutation of $Z E B 2$, so a different one from our patients. Furthermore, no spleen hypo/ aplasia has been described in previously reported patients with de novo c.2083C $>$ T or c.2761C $>$ T heterozygous mutations of ZEB2 found in patients 1 and 4 [11].

On the other hand, this report emphasizes the potential role of ZEB2 in human spleen development. This association makes this gene a possible new candidate for isolated congenital asplenia. Indeed all cases cannot be attributed to RPSA gene, suggesting a possible genetic heterogeneity. Although mutations of ZEB2 are generally associated with much more complex conditions, it cannot be excluded that some missense mutations could be responsible for apparently isolated asplenia [2].

\section{Acknowledgements}

The authors wish to thanks all colleagues providing support for this article, the families for their kindly cooperation and the reviewers for their positives remarks and useful suggestions.

\section{Author details}

${ }^{1}$ Hospices Civils de Lyon, Groupe Hospitalier Est, Service de Génétique et Centre de référence des anomalies du développement, Bron F-69677, France. ${ }^{2}$ Centre de recherche en Neurosciences de Lyon, Inserm U1028, CNRS UMR 5292, UCBL, équipe TIGER, Bron, France.

Received: 28 October 2013 Accepted: 27 December 2013

Published: 8 January 2014

\section{References}

1. Mahlaoui N, Minard-Colin V, Picard C, Bolze A, Ku CL, Tournilhac O, et al: Isolated congenital asplenia: a French nationwide retrospective survey of 20 cases. J Pediatr 2011, 158(1):142-148. 8 e1.
2. Bolze A, Mahlaoui N, Byun M, Turner B, Trede N, Ellis SR, et al: Ribosomal protein SA haploinsufficiency in humans with isolated congenital asplenia. Science 2013, 340(6135):976-978.

3. Garavelli L, Mainardi PC: Mowat-Wilson syndrome. Orphanet J Rare Dis 2007, 2:42.

4. Mowat DR, Croaker GD, Cass DT, Kerr BA, Chaitow J, Ades LC, et al: Hirschsprung disease, microcephaly, mental retardation, and characteristic facial features: delineation of a new syndrome and identification of a locus at chromosome 2q22-q23. J Med Genet 1998, 35(8):617-623.

5. Garavelli L, Donadio A, Zanacca C, Banchini G, Della Giustina E, Bertani G, et al: Hirschsprung disease, mental retardation, characteristic facial features, and mutation in the gene ZFHX1B (SIP1): confirmation of the Mowat-Wilson syndrome. Am J Med Genet Part A 2003, 116A(4):385-388.

6. Verstappen G, van Grunsven LA, Michiels C, Van de Putte T, Souopgui J, Van Damme J, et al: Atypical Mowat-Wilson patient confirms the importance of the novel association between ZFHX1B/SIP1 and NURD corepressor complex. Hum Mol Genet 2008, 17(8):1175-1183.

7. Zweier C, Thiel CT, Dufke A, Crow YJ, Meinecke P, Suri M, et al: Clinical and mutational spectrum of Mowat-Wilson syndrome. Eur J Med Genet 2005, 48(2):97-111.

8. Bassez G, Camand OJ, Cacheux V, Kobetz A, Dastot-Le Moal F, Marchant D, et al: Pleiotropic and diverse expression of ZFHX1B gene transcripts during mouse and human development supports the various clinical manifestations of the "Mowat-Wilson" syndrome. Neurobiol Dis 2004, 15(2):240-250.

9. Mowat DR, Wilson MJ, Goossens M: Mowat-Wilson syndrome. J Med Genet 2003, 40(5):305-310.

10. Rosado MM, Gesualdo F, Marcellini V, Di Sabatino A, Corazza GR, Smacchia MP, et al: Preserved antibody levels and loss of memory $B$ cells against pneumococcus and tetanus after splenectomy: tailoring better vaccination strategies. Eur J Immunol 2013, 43(10):2659-2670.

11. Dastot-Le Moal F, Wilson M, Mowat D, Collot N, Niel F, Goossens M: ZFHX1B mutations in patients with Mowat-Wilson syndrome. Hum Mutat 2007, 28(4):313-321.

doi:10.1186/1750-1172-9-2

Cite this article as: Pons et al.: ZEB2, a new candidate gene for asplenia. Orphanet Journal of Rare Diseases 2014 9:2.

\section{Submit your next manuscript to BioMed Central and take full advantage of:}

- Convenient online submission

- Thorough peer review

- No space constraints or color figure charges

- Immediate publication on acceptance

- Inclusion in PubMed, CAS, Scopus and Google Scholar

- Research which is freely available for redistribution 